\title{
A Puzzle about Reasons and Rationality
}

\section{Caj Strandberg}

\begin{abstract}
According to a guiding idea in metaethics, there is a necessary link between the concept of normative reasons and the concept of practical rationality. This notion brings up two issues: The exact nature of this link, and the nature of rationality. With regard to the first issue, the debate is dominated by a certain standard claim. With regard to the second issue, the debate is dominated by what I will refer to as 'subjectivism' and 'objectivism' about rationality, where the latter is assumed to be a necessary condition for the existence of categorical reasons. In this paper, it is argued that subjectivism is able capture an ordinary, non-technical, sense of 'rational' whereas objectivism is not. The basic reason is that objectivism fails to account for the essential connection between rationality, malfunctioning, and rational criticism. This means that we face a puzzle: While objectivism appears to be a necessary condition for the existence of categorical reasons, it fails to capture a central sense of 'rational'. It is finally argued that this puzzle can be solved by abandoning the standard claim about the link between reasons and rationality.
\end{abstract}

Keywords Normative reasons · Internalism - Externalism · Practical rationality Categorical reasons $\cdot$ Moral reasons $\cdot$ Rational criticism

\section{$1 \quad$ Introduction}

According to a guiding idea in metaethics, there is a necessary link between the concept of normative reasons and the concept of practical rationality. This notion brings up two issues: On the one hand the nature of this link, and on the other hand the nature of rationality. As regards the first issue, the debate is dominated by a certain standard claim stating that if a person has a reason to perform an action, she needs to have an appropriate desire in order to qualify as fully rational. As regards the second issue, there is a basic distinction between what I will refer to as 'subjectivism' and 'objectivism' about rationality. On subjectivism, what is rational for a person to desire depends on her subjective ends, whereas on objectivism it is independent of them. It is commonly presumed that objectivism is a necessary condition for the existence of categorical reasons.

The paper makes four main points. First, it argues for subjectivism, and against objectivism, on the grounds that the former is able to capture an ordinary, non-technical, sense of 'rational' while the latter is not. Second, it is argued that the explanation why objectivism might seem so plausible largely is due to the fact that the mentioned standard claim is taken for granted, rather than the plausibility of objectivism itself. Third, it is found that a fundamental puzzle emerges: While objectivism appears to be a 
necessary condition for the existence of categorical reasons, this view fails to capture the mentioned sense of 'rational'. Fourth, it is suggested that this puzzle can be solved by abandoning the standard claim.

In Sect. 2, I characterize the standard claim about the link between reasons and rationality. In Sect. 3, I characterize subjectivism and objectivism about rationality, and explain why objectivism is assumed to constitute a necessary condition for the existence of categorical reasons. In Sect. 4, I argue that subjectivism entails that the desires a person needs to have to be rational are accessible via a process of rational deliberation, whereas objectivism leaves open the possibility that they are inaccessible via such a process. In Sect. 5, I observe that in an ordinary, non-technical, sense of 'rational', there is an essential connection between rationality, mental functioning, and rational criticism. In Sect. 6, I provide three arguments to the effect that subjectivism is able to account for this connection, whereas objectivism is not, as a result of their different implications with regard to rational accessibility. ${ }^{1}$ In Sect. 7, I outline the puzzle I described above and the various options it sets before us. In Sect. 8, I suggest that the puzzle can be solved by giving up the mentioned standard claim.

\section{The Standard Claim about the Link between Reasons and Rationality}

It is generally agreed that there is a necessary link between the concept of normative reasons and the concept of rationality. Moreover, according to an extremely influential notion there exists a particular type of connection between them. In its most general formulation, it states is that if a person $S$ has a normative reason to $\varphi$, she needs to have a certain desire with regard to ping in order to be rational. In a well-known introduction to the debate, it is pointed out that a particular instance of this notion 'is common ground to contemporary theorizing about practical reason' (Cullity and Gaut (1997: 3)). Indeed, a number of renowned philosophers consider it as a platitude. ${ }^{2}$ It can be formulated as follows:

\footnotetext{
${ }^{1}$ The argument can be seen as a development of an argument put forward in Lillehammer (2002: 47-69).

${ }^{2}$ See e.g. Korsgaard (1986: 23); Wallace (1999: 217-218), and Setiya (2004: 268-269). Cf. Williams (1981: 101-113); Darwall (1983: 53); Smith (1994: 62, 150); Finlay (2009: 2-3), Parfit (2011: 5, 111118), and Broome (2013: Ch. 6). 'Desire' refers in this debate to a variety of motivating mental states ordinarily indicated by expressions such as 'want', 'value', 'care about', etc. It is not used in a way that commits to a particular metaphysical view of such states. What I call 'the standard claim' is sometimes called 'internalism', but I will reserve the latter term for another notion.
} 
Standard Claim: If a person $\mathrm{S}$ has a normative reason to $\varphi$, then she would have a desire to $\varphi$ if she were practically rational.

It is apt to start with some clarifications with relevance for the subsequent discussion. First, there are different formulations of the basic notion- e.g. the 'example model' and the 'advice model' - but since they are not relevant to my arguments I will not discuss them. ${ }^{3}$ Second, we will consider claims which concern normative reasons themselves, rather than claims which concern judgments about such reasons. Thus, the standard claim is about S's reason to $\varphi$, not S's normative judgment that she has a reason to $\varphi$. Third, we will be concerned with actual normative reasons rather than apparent or motivating reasons. As a result, I will understand 'rationality' as 'rationally under full information' rather than 'rationality under actual information'. In other words, I will consider S's rationality on the assumption that she has all relevant true non-normative beliefs and no relevant false non-normative beliefs. Thus, I will assume that $\mathrm{S}$ is fully informed about all non-normative facts about ping which are relevant as to whether she would desire to $\varphi$ if she were rational. ${ }^{4}$ Lastly, we will be concerned with pro tanto reasons rather than pro toto, or all-things-considered, reasons.

\section{Two Conceptions of Rationality}

The standard claim has a crucial implication: If a person $\mathrm{S}$ has a normative reason to $\varphi$, but does not have any desire to $\varphi$, she is practically irrational. It therefore raises the question what desires $\mathrm{S}$ needs to have in order to be rational.

The term 'practically rational', when applied to a person S, might refer to at least two different things with regard to her desires. ${ }^{5}$ First, it might refer to S's capacity to rationally deliberate in ways that are relevant for the aim of acquiring certain desires. A person $\mathrm{S}$ has the capacity to rationally deliberate insofar as she possess mental abilities that she can employ in accordance with certain rational considerations in a process of rational deliberation. Second, it might refer to a state $\mathrm{S}$ is in when she has certain desires. According to influential views, it is a state $S$ would be in after she has gone through a process of rational deliberation that is successful in the sense that she has acquired the desires representing the aim of the process. It is the second aspect the

\footnotetext{
${ }^{3}$ Smith (1995: 109-131). For criticism, see e.g. Sobel (2001: 226-235) and Bedke (2008: 104-106).

${ }^{4}$ See e.g. Williams (1981: 102-103) and Smith (1995: 112-113).
} 
standard claim refers to and with which I will be concerned. In what follows, I will presume that $\mathrm{S}$ is rational in the capacity sense but not that she is rational in the state sense.

There are two broad conceptions about practical rationality that I will refer to as 'subjectivism' and 'objectivism'. An intuitive manner of approaching these views is to think of them as expressions of two distinct perspectives.

The basic idea in subjectivism is that an assessment of a person S's rationality is to be made from a normative perspective which is constituted by her own subjective ends, where this perspective need not be shared by those who make the assessment. The significance of an assessment of rationality on this view is to establish what desires it would be rational for $\mathrm{S}$ to have given what desires she actually has.

As I will understand subjectivism, it makes two basic claims. The first consists in a procedural view of rationality and the second a natural consequence of it. (i) A person $\mathrm{S}$ is practically rational in the relevant respect insofar as she has the set of desires she would have were she to go through a process of rational deliberation which takes its point of departure in her set of actual desires. ${ }^{6}$ (ii) It is not the case that $\mathrm{S}$ in order to be rational needs to have any desire that is counterfactually independent of her set of actual desires. That is, it is not the case that $\mathrm{S}$ in order to be rational needs to have any desire which is such that even if her actual desires had been completely different than they are, she would need to have this desire. Consequently, what desires $\mathrm{S}$ needs to have to be rational might vary with her actual desires.

The claim in (ii) can be explicated as the following intrapersonal claim: There is no particular set of desires $\mathrm{S}$ needs to have in every possible world in order to qualify as rational, irrespective of what her set of actual desires amounts to in that world. Gloss: Assume that $\mathrm{S}$ has a certain set of desires $\mathrm{D}$ in possible world $\mathrm{W}$ and a different set of desires D' in possible world W'. It is not the case that, in order to be rational in W and W', S needs to have a set of desires $\mathrm{D}^{*}$ that is identical in $\mathrm{W}$ and $\mathrm{W}$ '?

\footnotetext{
${ }^{5}$ Cf. Broome (2013: 110) and Ridge (2014: 226). See also Copp (2015: 142-143).

${ }^{6}$ The phrase 'in the relevant respect' indicates that these claims merely specify rationality with regard to S's desires; a full account of her rationality also needs to comprise other components. See e.g. Bratman (1987: Ch. 2 and 3); Bratman (2000: 35-61); Svavarsdóttir (2008: 2-10), and Broome (2013: Ch. 5-11).

${ }^{7}$ Subjectivism also entails the following interpersonal claim: There are no particular set of desires that any person needs to have in order to qualify as rational. Gloss: Assume that S and S' have different sets of desires, $\mathrm{D}$ and $\mathrm{D}^{\prime}$. It is not the case that, in order for $\mathrm{S}$ and $\mathrm{S}$ ' to be rational, they need to have any set of desires $\mathrm{D}^{*}$ in common.
} 
There are different versions of subjectivism depending on what rational considerations a process of rational deliberation is taken to involve, but instrumental rationality, full imagination, and coherence are common suggestions. Accordingly, the process can be assumed to result in $\mathrm{S}$ having desires for the means that are necessary to satisfy her final ends, desires that sustain full imagination, and desires that are coherent with one another. It is not significant for this paper exactly what rational considerations such a process involve. ${ }^{8}$

The basic idea in objectivism is that an assessment of a person S's rationality is to be made from a normative perspective that need not be shared by the person herself in the sense of being constituted by her own subjective ends. The significance of an assessment of rationality on this view is to establish what desires it would be rational for $\mathrm{S}$ to have quite irrespective of what desires she happens to have.

As I understand objectivism, it makes the following basic claim: A person $S$ is practically rational in the relevant respect insofar as she has a set of desires of which at least a subset is counterfactually independent of her set of actual desires. Thus, objectivists deny (ii) in subjectivism. There are substantial versions of objectivism (which deny both (i) and (ii)) and objective procedural versions of this view (some of which accept (i)). In the next section, we will take a brief look at these options.

The basic claim of objectivism can be explicated as the following intrapersonal claim: There is a certain set of desires that $S$ needs to have in every possible world in order to be rational, irrespective of what her set of actual desires amounts to in that world. Gloss: Assume that $\mathrm{S}$ has a certain set of desires D in possible world $\mathrm{W}$ and a different set of desires D' in possible world W'. In order to be rational in W and $\mathrm{W}^{\prime}, \mathrm{S}$ needs to have a certain set of desires $\mathrm{D}^{*}$ that is identical in $\mathrm{W}$ and $\mathrm{W}$ '.

Now, the standard claim about the link between reasons and rationality can be combined with either subjectivism or objectivism about rationality. The standard claim in conjunction with subjectivism yields Internalism about Reasons: If a person $\mathrm{S}$ has a reason to $\varphi$, she would have a desire to $\varphi$ if she were rational, where this desire is not

\footnotetext{
${ }^{8}$ See e.g. Brandt (1979: Part I); Williams (1981: 104-105); Railton (1986: 7-17); Smith (1994: 158-161); Shemmer (2007: 326-348); Goldman (2009: Ch. 2), and Ridge (2014: Ch. 8). Cf. Svavarsdóttir (2008: 133).

${ }^{9}$ Objectivism also entails the following interpersonal claim: There is a certain set of desires every person needs to have in order to be rational. Gloss: Assume that S and S' have a different sets of desires, D and D'. In order to be rational, $S$ and S' need to have a certain set of desires $D^{*}$ in common irrespective of what their set of actual desires D and D' consist in.
} 
counterfactually independent of her actual desires. In that case, whether she has a reason to $\varphi$ would vary depending on her actual desires. The standard claim in conjunction with objectivism yields Externalism about Reasons: If $\mathrm{S}$ has a reason to $\varphi$, she would have a desire to $\varphi$ if she were rational, where this desire might be counterfactually independent of her actual desires. In that case, whether she has a reason to $\varphi$ would not vary depending on her actual desires. ${ }^{10}$ Consider now Categorical Reasons. As I understand this notion, it entails the following claim: If $\mathrm{S}$ has a categorical reason to $\varphi$, then she has this reason irrespective of what her actual desires consist in, which means that it cannot vary with them. It follows that externalism is compatible with the existence of categorical reasons whereas internalism is not.

\section{$4 \quad$ Rational Accessibility and Inaccessibility}

Subjectivism states that a person $\mathrm{S}$ is rational insofar as she has the desires she would have were she to go through a process of rational deliberation which takes its starting point in her actual desires. Moreover, there is no desire $\mathrm{S}$ needs to have in order to be rational that is counterfactually independent of her actual desires. As a result, subjectivism entails that $S$ would be able to acquire the desires she needs to have to be rational via a process of rational deliberation, since these desires simply are the desires that would be the result of such a process, whatever these desires consist in. Thus, subjectivism entails:

Rational Accessibility: In order to be practically rational, a person $\mathrm{S}$ needs to have (lack) a certain desire to $\varphi$ only if she would be able to acquire (lose) this desire via a process of rational deliberation.

Objectivism, by contrast, states that in order to be rational $\mathrm{S}$ needs to have certain desires that are counterfactually independent of her actual desires. Now, it is reasonable to think that the following type of scenario might occur on this view: $\mathrm{S}$ needs to have a certain desire to be rational, but there is no process of rational deliberation by which she

\footnotetext{
${ }^{10}$ The terminology varies in the literature. Internalism is sometimes understood to include (i) but not necessarily (ii). A view which includes (i) but denies (ii) is classified as externalist in my terminology. Cf. FitzPatrick (2004: 290-291).
} 
would be able to acquire it. ${ }^{11}$ That is, objectivism suggests that the following is possible:

Rational Inaccessibility: In order to be practically rational, a person $\mathrm{S}$ needs to have (lack) a certain desire to $\varphi$ even if she would not be able to acquire (lose) this desire via a process of rational deliberation.

Let me clarify this idea. According to objectivism, in order to be rational $\mathrm{S}$ needs to have certain desires that are counterfactually independent of her actual desires. That is, $\mathrm{S}$ needs to have certain desires in any possible world in order to be rational, irrespective of what actual desires she has in that world. In that case it seems extremely difficult to rule out that there is some possible world in which she is unable to acquire at least one of these desires via a process of rational deliberation, given her actual desires in that world. ${ }^{12}$ While objectivists state that there are particular desires $\mathrm{S}$ needs to have in order to be rational, and some of them suggest a process of rational deliberation that she might employ in order to try to acquire them, they do not generally seem to entail that it is impossible that a certain desire is rationally inaccessible in this specific sense. Indeed, subjectivism and objectivism are sometimes defined in terms of rational accessibility and inaccessibility, which might be taken to indicate that this assumption is fairly uncontentious. ${ }^{13}$ It would take a thorough discussion to outright demonstrate that objectivism is committed to rational inaccessibility. However, in view of the consideration above, it is plausible to think that objectivists would have grave

\footnotetext{
${ }^{11}$ I will formulate this point in terms of objectivism's intrapersonal claim, but it could just as well be formulated in terms of its interpersonal claim. Arguably, on objectivism there is some desire two persons need to have to be rational, but that cannot be acquired by both of them via a process of rational deliberation.

${ }^{12}$ This is compatible with the claim that in that world $\mathrm{S}$ is able to acquire the other desires she needs to have to be rational via a process of rational deliberation, given her actual desires in that world. Moreover, it is compatible with the claim that there is another possible world where $\mathrm{S}$ is able to acquire all the desires she needs to have to be rational via such a process, given the desires she has in that world. This type of issues is raised in the debate on Williams (1981: 101-113), but it is not always clear which of these possibilities that is under discussion. For relevant comments, see e.g. Cohon (1986: 545-556); Korsgaard (1986: 5-25); Hooker (1987: 42-44); Millgram (1996: 197-220); Shafer-Landau (2003: Ch. 7); Finlay (2009: 1-22); Lubin (2009: 273-291), and Markovits (2014: Ch. 3).

${ }^{13}$ Hooker and Streumer (2004: 58-59). It might perhaps be objected that if the requisite desires are very general or abstract, rational inaccessibility is ruled out on objectivism. However, given what just has been said I think it is plausible to assume that the claim holds for them as well. Nevertheless, this objection can be avoided by restricting the scope of rational inaccessibility: Rational Inaccessibility*: In order to be rational, a person $\mathrm{S}$ needs to have (lack) a certain desire to $\varphi$ even if she would not be able to acquire
} 
difficulties to rule out this possibility. Due to lack of space, I will therefore limit myself to some brief considerations in support of this contention.
A substantial view of rationality denies both
(i) and
(ii) in subjectivism.

According to this view, a person $\mathrm{S}$ is rational insofar as she has certain particular desires that are counterfactually independent of her actual desires. Moreover, there need not be any process of rational deliberation by which she can acquire these desires. ${ }^{14}$

Thus, on this view the possibility of rational inaccessibility is openly accepted as a consequence of the basic claim in objectivism. In a recent version of this view, it is claimed that S's rationality consists in 'responding to reasons'. As I understand this notion, it means that $S$ has reasons to perform certain actions, e.g. actions that realize states that are valuable, and in order to be rational she needs to 'respond to reason' in the sense of having desires to perform these actions, given that she has the relevant nonnormative beliefs. ${ }^{15}$ Derek Parfit writes that 'we all have decisive reasons to have certain desires, and to be substantively rational we must have these desires' (Parfit (2011: 78)), which suggests that 'responding to reason' means having the requisite desires under the mentioned condition. It is not claimed that there is any process of rational deliberation such that she would be able to acquire these desires irrespective of what her actual desires consist in.

However, there are objectivist procedural views of rationality. According to one version, a person $\mathrm{S}$ is rational insofar as she has certain desires which are counterfactually independent of her actual desires. Moreover, there is a process of rational deliberation which takes its point of departure in her set of actual desires which would result in her having such desires. ${ }^{16}$ (That is, it accepts (i), but denies (ii), in subjectivism.)

There are reasons to be skeptical that this view is able to prevent the possibility of rational inaccessibility in the specific sense detailed above. First, S might not have any desires that are even relevant to having a certain counterfactual desire she needs to

(lose) this desire via a process of rational deliberation, where this desire is needed to defend the existence of substantial categorical reasons.

${ }^{14}$ See e.g. Parfit (2011: Ch. 2) and FitzPatrick (2004: 285-318). Cf. Quinn (1993: 252-255) and Enoch (2011: Ch. 2-3).

${ }^{15}$ See e.g. Parfit (2011: 62-63). For criticism, see Broome (2013: 103-105).

${ }^{16}$ One explanation why this is assumed to be possible is that a process of rational deliberation is claimed to involve strict rational considerations as regards coherence among desires. See Smith (1994: 164-174, 187-189). 
have to be rational. ${ }^{17}$ We might imagine a possible world in which $\mathrm{S}$ has desires with regard to an extremely limited area of life. In that case, there might be no material in her actual desires such that she could come to have the requisite desire via a process of rational deliberation. Second, S might have desires that are extremely different from the desires she needs to have in order to be rational. In that case, S's actual desires and the requisite desire are so different that she cannot be brought to have the latter via such a process. These considerations might be in disagreement with Michael Smith's contention that people who engage in rational deliberation would converge in their desires. In this paper, I will not discuss Smith's convergence claim, mainly because it is not evident that it entails the impossibility of rational inaccessibility in the sense intended here. $^{18}$

According to another version, a person $\mathrm{S}$ is rational insofar as she has certain desires which are counterfactually independent of her actual desires. Moreover, on this alternative there is a process of rational deliberation which does not take its point of departure in S's set of actual desires, but which would make her acquire these desires. (Thus, it denies both (i) and (ii) in subjectivism.) The explanation is assumed to be that in order to be rational S needs to accept certain 'pure rational principles'. ${ }^{19}$

It is difficult to comment on this alternative as it is hard to find clear formulations of it, but there are grounds to be skeptical. First, it might be doubted that there is any pertinent process of rational deliberation by which $\mathrm{S}$ can acquire counterfactually independent desires via acceptance of 'pure rational principles'. It is reasonable to assume that acceptance of such a principle involves acceptance of a judgement which employs a normative concept, since it seems implausible that acceptance of a merely non-normative consideration by itself would be able to give rise to a particular desire, independent of any existing desires. ${ }^{20}$ However, we are concerned

\footnotetext{
${ }^{17}$ In particular, consider Smith's contention that a person's actual desires might be part of the relevant circumstances that determines her rationality and what reasons she has (Smith (1995: 112-125). Smith's view has also been subject to substantial criticism. See e.g. Hubin (1999: 355-361); Joyce (2001: Ch. 4); Hooker and Streumer (2004: 58-59); Kerstein (2006: 135-136), and Enoch (2007: 99-108).

${ }^{18}$ Smith (1994: 187-189). For criticism, see See Sobel (1999: 139-143). See also Smith (2011: 351-363), and (2012: 309-331).

${ }^{19}$ Korsgaard (1996: Ch. 3-4) might perhaps serve as an example of this view. However, depending on how her view is interpreted, it might also be seen as an example of the first objectivist procedural view; see FitzPatrick (2004: 290-291).

${ }^{20}$ According to a related view, if a person judges that she has a normative reason to $\varphi$, this guarantees that she has a desire to $\varphi$. See e.g. Nagel (1970: Ch. 5), and Scanlon (1998: Ch. 1). This type of internalism is not relevant to the present issue, which concerns the existence of reasons and not judgments about reasons.
} 
with reasons themselves rather than judgments about reasons or any other normative notion. ${ }^{21}$ Second, it is reasonable to doubt that the present view is able to prevent the possibility of rational inaccessibility. It might be argued that the mere fact that $S$ accepts, in the sense of believes, a 'pure rational principle' by itself need not have any implications for her desires. It seems plausible to think that there is a possible world in which $\mathrm{S}$ believes the truth or correctness of the relevant principle, but lacks a certain desire she needs to have to be rational. In line with this consideration, William FitzPatrick objects that there is a gap in Christine Korsgaard's view between accepting a principle and being moved to act in accordance with it. Even if it is granted that Korsgaard has shown that every rational agent needs to accept a certain normative principle, there is no guarantee that the person in question will be moved to act in accordance with it. ${ }^{22}$ It might be responded that 'accepting' a principle should be understood to entail 'employing' it. The idea would be that $\mathrm{S}$ is rational insofar as she accepts the principle in question which entails that she employs it, with the result that she has certain desires. However, it appears to be an open question what result S's employment of a certain principle will yield. There does not seem to be any guarantee that this result will not vary depending on her actual desires. Accordingly, Korsgaard claims in her renowned criticism of Bernard Williams's internalist view about reasons that he has not ruled out the possibility that a rational person has the ability to be motivated in accordance with certain principles applying to any rational being'considerations stemming from pure practical reason' (Korsgaard (1986: 21-23)) irrespective of their actual motivations. She does not argue, however, that employment of this ability guarantees that a person cannot fail to acquire a desire she needs to have to be rational. ${ }^{23}$

Thus, it is plausible to think that objectivism about has severe difficulties to rule out the possibility of rational inaccessibility understood in the specific sense delineated above. As we have seen, substantive objectivists readily accept this consequence of their view. Moreover, advocates of objective procedural views would need to undertake a

\footnotetext{
${ }^{21}$ It might be responded that S's true normative beliefs are relevant for what reasons she has. It seems implausible, however, that they would have any other relation to desires than her false normative beliefs.

${ }^{22}$ FitzPatrick (2005: 671-677). Cf. Setiya (2007: 94-99) and Bagnoli (2009: 477-493).

${ }^{23}$ Cf. Setiya (2007: 95-96). It might be suggested that this is what Kantians try to accomplish in their arguments for the categorical imperative. Confusingly, this argument seems to be an example of the first objectivist procedural view. Moreover, it appears too weak to be able to supply all the desires $\mathrm{S}$ needs to have to be rational. It might exclude certain desires, but it is implausible to think that it will generate new desires, which is needed to defend the existence of substantial categorical reasons.
} 
huge argumentative task in order to show that it does not apply. So, even if it would not be entirely obvious that there is not any version of objectivism that can prevent this possibility, it is fair to say that this claim is quite plausible and that it is those who oppose it that have the burden of proof.

\section{$5 \quad$ Rationality, Mental Functioning, and Rational Criticism}

It is reasonable to suggest that in an ordinary, non-technical, sense of 'rational' there is a close connection between rationality and a certain type of criticism. Derek Parfit writes:

When we call some act 'rational', using this word in its ordinary, non-technical, sense, we express the kind of praise or approval that we can also express with words like 'sensible', 'reasonable', intelligent', and 'smart'. We use the word 'irrational' to express the kind of criticism that we express with words like 'senseless', 'stupid', 'idiotic', and 'crazy' (Parfit (2011: 33)).

Joshua Gert implies that in this sense of 'rational' there is in addition an intimate connection between rationality, a certain type of mental functioning, and the mentioned type of criticism:

[W]e are using the term 'subjectively irrational' to categorize those actions that involve a kind of failure in practical mental functioning' $[. .$.$] whether or not these failures are sufficiently extreme$ to have much importance in particular cases. That is, 'subjectively irrational' is meant to collect the spectrum of actions that range from 'silly' and 'stupid', through 'boneheaded' and 'a bad idea,' all the way up to 'crazy', 'insane,' and worse (Gert (2004: 143)). ${ }^{24}$

Let me start with clarifying the connection between the three relevant notions: rationality, mental functioning, and criticism. First, the term 'rational' and its derivations in these quotations are attributed to actions. However, they can also be attributed to persons, desires, and other entities. Indeed, as has been pointed out, these terms are primarily attributed to persons and only derivatively to other entities. ${ }^{25}$ Second, as the quotation from Gert indicates, in this sense of 'rational' claims about rationality entail claims about practical mental functioning. Intuitively, if a person $\mathrm{S}$ is irrational, something is wrong with her and the relevant type of wrongness consists in a

\footnotetext{
${ }^{24}$ Cf. Bedke (2008: 98-100) and Ridge (2014: Ch. 8). Gert talks about 'subjective rationality' rather than rationality under full information. However, this difference is not relevant in the present context. On the assumption that $\mathrm{S}$ is fully informed, the mentioned considerations as regards mental functioning and criticism apply to her.

${ }^{25}$ See e.g. Svavarsdóttir (2008: 1) and Broome (2013: 71).
} 
certain type of mental malfunctioning. In particular, the claim that $S$ is irrational in the indicated sense entails that she is practically mentally malfunctioning in that she does not operate properly in a way which bears on some of her practical enterprise, e.g. what she desires to do. Third, we might claim that a person $S$ is rational or irrational in a particular respect. When we make claims about people's rationality, we do not generally make claims about their overall rationality, but about a certain aspect of it. In this paper, I am particularly interested in the following aspect: If $\mathrm{S}$ needs to have a certain desire to $\varphi$ in order to be rational, but lacks it, she is irrational in lacking a desire to $\varphi$. In view of what was said above, it follows that $\mathrm{S}$ is malfunctioning with regard to a particular aspect of her practical mental functioning, viz. in lacking a desire to $\varphi$. Finally, as Parfit points out, in this sense of 'rational' considerations about rationality justify certain types of critical evaluations. For example, the fact that $\mathrm{S}$ is irrational, and consequently malfunctioning in a particular respect, justifies certain type of criticism against her, what I will call 'rational criticism'. The mentioned type of criticism might be expressed by saying that $\mathrm{S}$ is 'irrational', but we might also use expressions such as 'unreasonable', 'silly', 'stupid', etc.

Thus, in an ordinary, non-technical, sense of 'rational' there seems to be an intimate connection between the three notions of rationality, mental functioning, and rational criticism. In what follows, I will be interested in a particular instance of this connection:

The Connection: If a person $\mathrm{S}$ is irrational in lacking a desire to $\varphi$, she is practically mentally malfunctioning in this respect, which makes rational criticism against her justified.

As mentioned, I maintain that there is a certain central sense of 'rational' that entails this connection between the three notions. Importantly, this claim is compatible with the term having other, less central, senses which do not entail it. I will return to this consideration below.

\section{Subjectivism, Objectivism, and Rationality}

In order to facilitate the subsequent discussion, it might be helpful to start with illustrating the relevant difference between subjectivism and objectivism. Consider: 
Case 1. Moral case. Ada has the desires that would be the result of a process of rational deliberation which takes its starting point in her actual desires. However, she does not have any desire to help other people in need. There is no process of rational deliberation that would make her acquire this desire.

Case 2. Prudential case. Ada has the desires that would be the result of a process of rational deliberation which takes its starting point in her actual desires. However, she does not have any desire to avoid pain. There is no process of rational deliberation that would make her acquire this desire.

Subjectivism entails that the desires a person needs to have in order to be rational are rationally accessible to her via a process of rational deliberation. In Cases 1 and 2, Ada has the desires she would have were she to go through such a process, which means that, on this view, she is not irrational in lacking the two desires. By contrast, on objectivism the desires $\mathrm{S}$ needs to have to be rational might be rationally inaccessible to her. Thus, this view leaves open the possibility that Ada is irrational in lacking the desires in question.

\subsection{Preliminary Problems for Objectivism}

It is noteworthy that arguments for objectivism about rationality standardly maintain that this view enables us to account for our notion of the relation between reasons and desires. $^{26}$ The most common type of consideration is presumably that a person $\mathrm{S}$ might have a categorical moral reason to $\varphi$ quite irrespective of what her actual desires consist in. However, such arguments do not provide particularly strong support to objectivism as such, since they concern the relation between reasons and desires rather than the relation between rationality and desires, which after all is the subject matter of this view. Similarly, it is sometimes maintained that $\mathrm{S}$ might have a categorical prudential reason to $\varphi$ quite irrespective of what her actual desires consist in. Accordingly, Parfit argues that a person has a reason to avoid agony even if she would be unable to acquire

\footnotetext{
${ }^{26}$ For overviews of type of arguments, see e.g. Brink (1992: 1-26); Cullity and Gaut (1997: 1-27), and Finlay and Schroeder (2008).
} 
a desire to do so after a process of rational deliberation. ${ }^{27}$ It is striking, however, that the point generally seems to be that a person might have a reason to, say, avoid pain even if she would not have a desire to do so, not that she would lack in rationality in the absence of such a desire.

Now, there is a ready explanation of why it is widely presumed that our notion of the relation between reasons and desires provide an argument for objectivism. As we saw in Sect. 2, the standard claim about the relation between reasons and rationality is taken for granted in the debate. The standard claim in conjunction with objectivism (yielding externalism) entails that $\mathrm{S}$ might have a reason to $\varphi$ quite irrespective of what her actual desires consist in, whereas the standard claim in conjunction with subjectivism (yielding internalism) entails that this is not so. Thus, since the standard claim is presumed in the debate, we are led to think that the assumption that there are categorical reasons provides support to objectivism. Indeed, we are even led to think that objectivism is required to defend the existence of categorical reasons. However, we have seen that the assumption that there are categorical reasons does not by itself provide any support to objectivism, but does so only if the standard claim is presupposed. Moreover, in Sect. 8 we will see that if the standard claimed is denied, a person can have a categorical reason also according to subjectivism.

It might next be observed that to the extent objectivists do argue by appealing to our notion of the relation between rationality and desires, rather than the relation between reasons and desires, the support of their view is not particularly strong.

Consider first a moral case like 1. Objectivists might try to make plausible that it would be irrational for Ada to lack a desire to perform a morally required action even if this desire is rationally inaccessible to her. One problem with this way of arguing is that our notion of the relation between rationality and desires to perform such actions does

\footnotetext{
${ }^{27}$ Parfit (2011: 73-82). Cf. Millgram (1996: 201-204) and Shafer-Landau (2003: 185-186). It might be objected that on the standard claim it follows that the person in question would be irrational. However, it still seems significant that the argument is formulated in terms of reasons rather than rationality, especially given that both options are available on this claim. Moreover, there are other indications that intuitions about reasons are what drive the argument. After having presented the agony argument, Parfit comments on the relation between rationality and desires. He imagines that subjectivists might respond that someone who is rational would have a desire to avoid agony. Parfit replies that this defence is ambiguous since it tends to conflate a subjectivist ('procedural') and an objectivist ('substantive') view of rationality (Parfit (2011): 78)). It is symptomatic that he seems to regard the relation between rationality and desires as something subjectivists can appeal to so as to avoid the agony argument, rather than as a further argument against their view. Similarly, Warren Quinn argues that a person might have a desire to turn on radios without having any reason to do so (Quinn (1993: 236-246)); he does not argue that the
} 
not seem to provide particularly strong support to this view. Indeed, subjectivists sometimes argue for their view by pointing out that it seems possible to have a moral reason to $\varphi$, lack a desire to $\varphi$, but still be perfectly rational. ${ }^{28}$ The view I will defend leaves open this possibility. In any case, we do not appear to regard it as obviously irrational to lack desires to perform actions that we classify as morally required.

Consider next a prudential case like 2. Objectivists might argue that it would be irrational for Ada to lack a desire to perform a certain prudentially preferable action even if this desire is rationally inaccessible to her. The strongest versions of this argument presumably concern cases which involve mental states of pleasure and pain. It might for instance be suggested that Ada would be irrational in lacking a desire to avoid pain even if it is rationally inaccessible to her. ${ }^{29}$ In response, it can be contended that plausible accounts of what is good and bad with being in such mental states refer to desires in a way which means that objectivists cannot appeal to them in their arguments. ${ }^{30}$ For example, on a plausible view it is bad to have a pain sensation only if one dislikes having that type of sensation. Now, dislike, properly understood, is presumably a type of desire. However, if it is not bad for Ada to have a sensation of pain unless she desires not have that type of sensation, it is questionable whether she must to be irrational if she lacks a desire to avoid pain. This consideration raises difficult questions about what is good or bad for a person, and the relation of these notions to the notion of rationality, which cannot be addressed here. Moreover, I will suggest a view which leaves open that a person has a prudential reason to, say, avoid pain even if it would not strictly speaking be irrational for her to lack a desire to do so.

person is irrational in having this desire. By the same token, Thomas Nagel's various arguments appeal to the relation between reasons, not rationality, and desires (Nagel (1970: Ch. 6)).

${ }^{28}$ See e.g. Foot (1978 (1972): 161-162). Cf. Brink (1992: 9, 21); Gert (2004: Ch. 2); Copp (2010: 150159), and Copp (2015: 134-159).

${ }^{29}$ Cf. Parfit's 'agony argument': Parfit (2011: 73-82). It might be objected that there are other desires that it would be irrational to lack, such as a desire to avoid death or be able to speak. However, I think these examples would be more contentious than a desire to have or avoid certain experiences, which presumably explains why the latter usually is employed in the argument. For instance, it is not obvious that it would be irrational for Ada to lack a desire to avoid death given that certain facts hold true about her life and that she has certain other desires. An argument that appeals to lack of a desire to avoid pain has intuitive force precisely because it might seem plausible that Ada has a reason to avoid pain, or would be irrational if she lacks a desire to do so, irrespective of what holds true of her in other respects.

${ }^{30}$ See Sobel (2011: 55-60) and Heathwood (2011: 92-94). Parfit accepts the mentioned view of why it is bad for a person to be in pain, but maintains that dislikes do not belong to the type of attitudes subjectivists can employ in defence of their view. Sobel and Heathwood argue, convincingly in my view, against this assumption. Moreover, Sobel makes plausible that on subjectivism it would be irrational not to have a desire to pursue the necessary means to satisfy a future rational desire (Sobel (2011: 60-66)). 
This brief discussion provides some preliminary grounds to think that arguments for objectivism are not as strong as one first might be inclined to think. In the next section, I will provide three closely connected arguments in support of subjectivism and against objectivism.

\subsection{The Argument from Malfunctioning}

In Sect. 5, we noticed a certain connection: If a person $S$ is irrational in lacking a desire to $\varphi$, she is practically mentally malfunctioning in this respect, which justifies rational criticism against her. In this subsection, I will focus on the first part of this connection: If $S$ is irrational in lacking a desire to $\varphi$, she is malfunctioning in this respect.

As mentioned, to claim that $\mathrm{S}$ is malfunctioning entails that there is something wrong with the way she operates in a certain respect. ${ }^{31}$ Thus, I will understand a claim to the effect that $S$ is malfunctioning in lacking a desire to $\varphi$ to entail that something is wrong with the way she operates with relevance for her having a desire to $\varphi$.

Subjectivism is able to account for the connection between irrationality and malfunctioning. According to this view, $\mathrm{S}$ is rational insofar as she has the desires she would have were she to go through a process of rational deliberation which takes its starting point in her actual desires. Moreover, there is no desire S needs to have in order to be rational that is counterfactually independent of her actual desires. As a result, to be rational $S$ needs to have a desire to $\varphi$ only if it is rationally accessible to her, i.e. if she can acquire a desire to $\varphi$ via a process of rational deliberation. For instance, assume that Ada needs to have a certain desire to be rational but that she lacks it and therefore is irrational in this regard. It follows that she is malfunctioning in the sense that something is wrong with how she operates in a particular respect. Especially, she has failed to properly exercise her mental abilities in accordance with the relevant rational considerations in a process of rational deliberation.

By contrast, objectivism has difficulties to account for the connection under consideration. One difficulty with objectivism is this: If a desire to $\varphi$ is rationally inaccessible to $\mathrm{S}$, it does not seem that she is malfunctioning in lacking this desire. However, if $\mathrm{S}$ is not malfunctioning in lacking a desire to $\varphi$, she is not irrational in this

\footnotetext{
${ }^{31}$ Alternatively, she was malfunctioning at an earlier point in time with the consequence that she now lacks a desire to $\varphi$. I will take this possibility to be covered by the above formulation.
} 
respect according the mentioned connection. As a consequence, the objectivist implication that $\mathrm{S}$ might be irrational in lacking a desire to $\varphi$ although it is rationally inaccessible to her appears untenable. ${ }^{32}$

To illustrate, consider Ada in cases 1 and 2. Ada lacks a desire to help other people in need or to avoid pain. Let us assume that on objectivism she needs to have the desire in question in order to be rational. However, since the desire is rationally inaccessible to her, there is no process of rational deliberation which could make her acquire it. In such a case, it seems implausible to maintain that Ada is malfunctioning in lacking this desire in the relevant manner. There are in particular two considerations that support this line of argument.

First, if Ada were malfunctioning, there would be something wrong with the way she operates. However, if a certain desire is rationally inaccessible to her, and there consequently is no process of rational deliberation which can make her acquire the desire, it does not seem to be anything wrong with how she operates in the relevant manner. In particular, there cannot be anything wrong with how Ada operates in the sense that she has failed to exercise her relevant mental abilities by employing them in rational deliberation, with the consequence that she does not have the desire. Hence, she is not malfunctioning in lacking the desire in question.

Second, cases such 1 and 2 are compatible with the possibility that Ada has gone through a process of rational deliberation without having acquired a certain desire she needs to have in order to be rational. In Sect. 4, it was argued that on objectivism such a desire might be rationally inaccessible to her. In particular, whereas objectivists claim that a person needs to have certain desires to be rational, and might suggest a process of rational deliberation that she can employ to try to acquire them, they cannot plausibly claim that there is any guarantee that she acquires the desire in question via such a process quite irrespective of what her actual desires consist in. This entails that Ada might fail to acquire a desire she needs to have to be rational in spite of having gone through a process of rational deliberation. In other words, on objectivism Ada might have exercised the relevant mental abilities without coming to have the desire in question. In such a case, the claim that Ada is malfunctioning in lacking the desire seems unfounded.

\footnotetext{
${ }^{32}$ Cf. Lillehammer (2002: esp. 53, 63).
} 
Objectivists might want to respond that Ada is malfunctioning in the sense that she lacks a certain desire she needs to have in order to be rational. However, this response runs contrary to the arguments above that are founded on the connection between irrationality and malfunctioning, which constitutes an aspect of the central sense of 'rational'. Especially, it neglects that if a person is malfunctioning, something is wrong with the way she operates. The mere fact that Ada lacks a certain desire does not by itself mean that she is malfunctioning, since it need not have anything to do with the way she operates. Objectivists may want to insist that Ada is malfunctioning in the sense that she operates in the absence of a desire she needs to have to be rational. In response, recall the connection: If $\mathrm{S}$ is irrational in lacking a desire to $\varphi$ (i.e. a desire she needs to have to be rational), she is malfunctioning in this respect, i.e. with respect to lacking that particular desire. As far as I can see, the response fails to account for in what respect Ada is malfunctioning in lacking a particular desire she needs to have in order to be rational. It rather seems to state that there is a certain desire Ada needs to have to be rational and then goes on to maintain that she is malfunctioning if she operates without employing it. ${ }^{33}$

Moreover, I think subjectivism can explain why the contention that Ada needs to be irrational even if the desire in question is rationally inaccessible to her might seem plausible. First, it might seem to get support from the assumption that a person $\mathrm{S}$ cannot have a reason to, for instance, help another person in need unless it would be irrational for her to lack a desire to perform the action. However, my arguments do not concern the notion of reasons, but the notion of rationality. Furthermore, this assumption rests on the standard claim that I think should be denied. As we shall see, if this claim is contested subjectivists can argue that $\mathrm{S}$ has a reason to, say, help someone in need, even if it would not be irrational for her to lack a desire to do so. Second, it might rest on a conflation as regards what constitutes the relevant object of the charge of irrationality. As mentioned, it might be claimed both about a person and about an action that she or it is irrational. It is the former that is relevant in the present context. The mentioned contention might seem to get support from the intuition that there are certain actions

\footnotetext{
${ }^{33}$ Objectivists may want to reply that in order for something to count as a process of rational deliberation at all, it needs to be successful in the sense of resulting in Ada acquiring a desire she needs to have to be rational. However, this would merely be a terminological manoeuvre that would not affect the basic point. Especially, Ada might still be unable to acquire the desire in question by exercising her abilities in rational deliberation.
} 
that simply are irrational. We classify certain types of actions as 'irrational' on various grounds without considering the mental states of the persons who perform them, for example because these actions appear 'strange', 'incomprehensible', 'weird', etc. However, this does not mean that a particular person who lacks the corresponding desire needs to be irrational irrespective of whether it is rationally accessible to her. Third, the contention might seem to get support from the intuition that there must be something wrong with a person who lacks a certain desire even if she has undergone a process of rational deliberation without acquiring it. However, subjectivism is compatible with this intuition, although there is nothing wrong with her from a strictly rational perspective on this view. After all, we evaluate people from various perspectives. For example, it can be claimed that there is something morally or prudentially wrong with a person who lacks the relevant desire even if she is unable to acquire it via a process of rational deliberation. Fourth, subjectivism can readily explain why we might be led to think that someone who lacks a certain desire fails in rationality. We are presumably warranted to suppose that most people we regard as rational would have such a desire. The underlying explanation is that we are warranted to assume that most people have actual desires such that were they to think matters through in a rational manner, they would acquire certain desires. Lastly, it should be stressed that I merely maintain that the connection holds for a central sense of 'rational'. Thus, my arguments are compatible with there being other senses of the term according to which a person is irrational in lacking a certain desire even if she is not malfunctioning in the relevant respect. The previous point provides a partial explanation of why we use 'rational' in such a sense: As we are warranted to assume that someone we regard as rational would have certain desires, we might think she fails in rationality even if she does not comply with the connection.

\subsection{The Argument from Rational Criticism}

In this subsection, I will focus on the following part of the connection: If a person $S$ is irrational in lacking a desire to $\varphi$, it is justified to direct rational criticism against her.

Subjectivism is able to account also for this part of the connection. According to this view, $\mathrm{S}$ needs to have a desire to $\varphi$ only if it is rationally accessible to her. For example, assume that Ada needs to have a certain desire in order to be rational. It follows that if she does not have this desire, she has failed to exercise the relevant 
abilities employed in rational deliberation. As a consequence, it might be justified to direct rational criticism against her for lacking the desire in question. ${ }^{34}$

By contrast, objectivism does not seem to be able to account for this connection. One difficulty with objectivism is this: If a desire to $\varphi$ is rationally inaccessible to $S$, it does not seem justified to criticize her for lacking this desire. However, if it is not justified to criticize $S$ for lacking a desire to $\varphi$, she is not irrational in this respect on the mention connection. As a consequence, the objectivist implication that $\mathrm{S}$ might be irrational in lacking a desire to $\varphi$ although it is rationally inaccessible to her seems implausible.

Again, consider Ada in cases 1 and 2. Ada lacks a desire to help others or to avoid pain. Let us assume that on objectivism she needs to have the desire in question in order to qualify as rational. However, since the desire is rationally inaccessible to her, there is no process of rational deliberation which could make her acquire it. In such a case, it seems implausible to direct rational criticism against her for lacking the desire in question. There are in particular two considerations that that provide support to this line of argument.

First, I argued earlier that if a certain desire is rationally inaccessible to Ada, she is not malfunctioning in lacking it. However, if she is not malfunctioning in lacking the desire, she can hardly be subject to the relevant type of rational criticism, since there is no ground for such criticism. Plausibly, the reason for claiming that someone is irrational in lacking a certain desire is that it is something wrong with her because she lacks it, i.e. that she is malfunctioning in this respect. As this ground for rational criticism does not exist in the absence of malfunctioning, such criticism seems unfounded in this case.

Second, in order for this rational criticism of Ada to be justified, it has to be the case that she, in at least in principle, should be able to avoid it in an appropriate manner. It would not be justified to criticize a person for lacking a desire by claiming that she is irrational if there is nothing she can do to acquire it by improving in any relevant manner. However, if the desire in question is rationally inaccessible to Ada, there is virtually no way she can improve further in terms of rationality so as to acquire it. In particular, there are no further mental abilities which she can exercise by employing

\footnotetext{
${ }^{34}$ However, this does not mean that rational criticism always is appropriate or has any practical function in such a situation. Cf. Svavarsdóttir (2008: 30-33) and Setiya (2004: 274-277, 282).
} 
them in a process of rational deliberation, and no further rational considerations she can take into account in doing so, which would make her acquire the requisite desire. In that case directing rational criticism against her for lacking the desire would not be warranted.

It might be contended that it can be justified to direct moral blame against a person $\mathrm{S}$ for not having a desire to $\varphi$ even if it is rationally inaccessible to her. For instance, it might be thought that it is justified to blame Ada in Case 1 even if she cannot acquire the desire in question via a process of rational deliberation. This consideration raises intricate questions about the connection between rational criticism and blame that cannot be addressed here. However, for present purposes it suffices to make two observations. First, what I have said is fully compatible with the mentioned possibility. In particular, I have not argued that it is justified to direct moral blame against $\mathrm{S}$ for lacking a desire to $\varphi$ only if it is rationally accessible to her. Rather, it has been argued that it is justified to direct rational criticism against $\mathrm{S}$ for lacking a desire to $\varphi$ only if this is the case. ${ }^{35}$ Second, my view is not committed to there being any relevant asymmetry between blame and rational criticism with regard to rational accessibility. Indeed, developments in recent philosophy of blame can be employed to argue that they behave in the same manner in this regard. ${ }^{36}$

\footnotetext{
${ }^{35}$ There are a number of different views about blame in the literature, but they generally seem to suggest that blame is not, or not merely, an instance of rational criticism. For example, according to one view blame is characterized by feelings of resentment, indignation, or guilt (Wallace (1994)). According to an alternative view, blame entails a judgment to the effect that a person has acted in a manner which impairs meaningful interpersonal relations (Scanlon (2008)). Neither of this is necessarily the case as regards rational criticism. This suggests that it should not be presumed at the outset that blame and rational criticism are symmetric as regards rational accessibility.

${ }^{36}$ In the contemporary literature on blame, there is a distinction between different types of moral responsibility and blame (see e.g. Watson (1996: 227-248) and Fischer and Tognazzini (2011: 381-417)). A person $\mathrm{S}$ can be blamed in the attributability sense on grounds of her character and in the accountability sense on grounds that exceed facts about her character, e.g. because she fails to perform a certain action that she is in the position to perform or fails to have a desire that she is able to acquire. The distinction means that $\mathrm{S}$ might be blamed for something (e.g. lacking a desire to $\varphi$ ) in the attributability sense because it reflects her bad moral character, even if she is cannot be blamed in the accountability sense (e.g. because a desire to $\varphi$ is not rationally accessible to her). In a similar manner, there should be a distinction between rational criticism in the attributability sense an in the accountability sense. It would mean that $\mathrm{S}$ can be rationally criticized for something (e.g. lacking a desire to $\varphi$ ) in the first sense because it reflects her bad rational capacity, even if she cannot be blamed in the second sense (e.g. because a desire to $\varphi$ is not rationally accessible to her). It might then be suggested that blame and rational criticism are symmetric with regard to rational accessibility. That is, it might be suggested that $\mathrm{S}$ can be blamed or rationally criticized in the accountability sense for lacking a desire to $\varphi$ only if it is rationally accessible to her, but that she can be blamed or rationally criticized in the attributability sense even if this is not the case.
} 
Moreover, my view is not vulnerable to a renowned argument against internalism based on the notion of moral blame. ${ }^{37}$ The argument starts with the assumption that it is justified to morally blame $S$ for not ping only if she has a sufficiently strong reason to $\varphi$. (Presumably, the same applies to having a desire to $\varphi$.) According to internalism, if $\mathrm{S}$ has a reason to $\varphi$, she would have a desire to $\varphi$ if she were rational, where rationality is understood in line with subjectivism. As a result, whether $\mathrm{S}$ has a reason to $\varphi$ would vary with her actual desires. However, it might be argued that $\mathrm{S}$ can be blamed for not ping quite irrespective of what her actual desires consist in. Importantly, this is an argument against internalism and not against subjectivism, which means that it does not affect my arguments. Moreover, since it is an argument against internalism, it presumes the standard claim. In Sect. 8, I will suggest that if this claim is denied, $\mathrm{S}$ might have a reason to $\varphi$ irrespective of what her actual desires consist in, also according to subjectivism. As a result, she might be accordingly blamed for not ping.

\subsection{The Argument from the Function of Rational Criticism}

It might further be argued that subjectivism provides a more straightforward account of the function of rational criticism than objectivism.

The practice of directing rational criticism plausibly serves a number of functions. It seems reasonable, however, to suggest that it has an important practical function in that it tends to influence people's actions and desires. ${ }^{38}$ Thus, it seems generally to be the case that if a person $\mathrm{S}^{*}$ directs criticism against a person $\mathrm{S}$ for being irrational in not ping, or for lacking a desire to $\varphi$, a function of this criticism is to influence $S$ to $\varphi$, or acquire a desire to $\varphi$. The clearest example of this function is perhaps when $\mathrm{S}^{*}$, in order to advice $\mathrm{S}$ to $\varphi$, or desire to $\varphi$, directs rational criticism against $\mathrm{S}$ on these grounds. ${ }^{39}$ For example, Bertie might advise Ada to accept an offer to

\footnotetext{
${ }^{37}$ For a clear account of the connection between reasons and blame, see Skorupski (2010: 290-301). Bernard Williams considers this argument and responds to it in Williams (1995: 35-45). For clarifications and critical assessments, see Sobel (2007: 149-170) and Skorupski (2007: 73-103). Internalists cannot employ the distinction between different types of blame to avoid this objection, since their view entails that $\mathrm{S}$ would not even have a reason to $\varphi$ if she would not be able to acquire a desire to $\varphi$ in a process of rational deliberation.

${ }^{38}$ Similarly, Svavarsdóttir argues that an account of rationality should account for the "corrective mechanisms though which pressure is exerted on agents' which would enable it to make 'crucial contact with the ordinary notion of rationality as applied to agents' (Svavarsdóttir (2008: 32). Cf. Ridge (2014: Ch. 8).

${ }^{39}$ Cf. Williams (1995: 36) and Setiya (2004: 276).
} 
get a new flat by, among other things, expressing his view that she is crazy in not wanting it. Moreover, $\mathrm{S}^{*}$ 's criticism might be accompanied by recommendations of some procedure which would enable $\mathrm{S}$ to acquire the desire or carry out the action.

The view that rational criticism has the function of influencing is strengthened by the observation that rational criticism generally is accompanied by certain type of reactive attitudes. Thus, it is generally the case that if $S^{*}$ directs criticism against $S$ for being irrational in not $\varphi$ ing, or for lacking a desire to $\varphi$, we assume that $S^{*}$ has a certain attitude towards S not $\varphi$ ing or lacking a desire to $\varphi$. For example, if Bertie says that Ada is crazy in not wanting the flat she is offered, we take him to convey a certain attitude towards her lacking the desire in question, e.g. concern, frustration, or irritation. It is a well-known phenomenon that we can influence other people by letting them know about our attitudes in relation to their actions and desires. Thus, it is plausible to assume that the fact that rational criticism is accompanied by certain types of attitudes is a device by which it can serve its practical function of influencing people's actions and desires.

In order to avoid misunderstanding, these claims need to be qualified. First, the claim that rational criticism generally has as a function to influence should not be understood to imply that a single person $S^{*}$ has the purpose to influence $S^{\prime}$ 's actions or desires. Rather, we should think of it as a general function of rational criticism of which we need not be consciously aware. Second, $\mathrm{S}^{*}$ 's rational criticism fulfils the function to influence only given that she does not add any further claims that annul or modify the function of the original claim.

Subjectivism is in the position to provide a fairly simple account for the practical function of rational criticism. According to this view, $\mathrm{S}$ needs to have a desire to $\varphi$ in order to be rational only if it is rationally accessible to her. This means that $\mathrm{S}^{*}$ 's rational criticism against $\mathrm{S}$ for not ping, or for lacking a desire to $\varphi$, might fulfil its function. That is, it is possible, at least in principle, that $\mathrm{S}$ in the light of $\mathrm{S}^{*}$ 's criticism starts to exercise the abilities employed in rational deliberation to the practical enterprise in question and as a result $\varphi s$ or acquires a desire to $\varphi$.

By contrast, it seems that objectivism is forced to employ a less straightforward account of the practical function of rational criticism. According to this view, it is possible that $S$ needs to have a desire to $\varphi$ in order to be rational even if it is rationally inaccessible to her. This entails that there is no way $\mathrm{S}$ can improve rationally so as to acquire a desire to $\varphi$. In particular, there are no abilities employed in rational 
deliberation that $\mathrm{S}$ can exercise and which, even in principle, would result in her having a desire to $\varphi$. In that case, $S^{*}$ 's rational criticism against $S$ for not having a desire to $\varphi$ cannot fulfil its practical function. Now, objectivists might respond that people in general would be able to acquire the desires they need to have to be rational via a process of rational deliberation, although there are single individuals who would not be able to do so. As a consequence, in most cases rational criticism would be able to fulfil its practical function also on their view. However, I am unsure to what extent this line of reasoning is open to objectivists in general. As far as I understand, on at least some versions of objectivism these desires are quite difficult to acquire via a process of rational deliberation, in which case the mentioned account is not available. ${ }^{40}$

Thus far, I have argued that subjectivism is able to account for a standard, nontechnical, sense of 'rational' in which case there is a certain connection between rationality, malfunctioning, and rational criticism, whereas objectivism is not able to do so. It might be responded that we sometimes take a subjectivist and sometimes an objectivist perspective on people's rationality, and that the term has two ordinary, nontechnical, senses, thus being genuinely ambiguous. First, in that case it is admitted that subjectivism is correct about a central sense of 'rational' which principally is what I need for my arguments. Second, I think it could be maintained that the subjectivist sense of 'rational' is the central one even if it would turn out that it is not the only ordinary, non-technical, sense. The basic reason is that it is able to explain the essential connection between, on the one hand, rationality and, on the other hand, malfunctioning, rational criticism, and the function of such criticism. Alternatively, it

\footnotetext{
${ }^{40}$ For example, this might be the case for objectivists of a Kantian stripe. In the last subsection, it was mentioned that my position leaves open that it might be justified to blame $S$ for lacking a desire to $\varphi$ even if it is rationally inaccessible to her. It might then be thought that if blame is an instance of rational criticism, $\mathrm{S}^{*}$ 's blame against $\mathrm{S}$ for not having a desire to $\varphi$ cannot fulfil its practical function in such a case. In response, let me make three brief comments. First, objectivists do not have any advantage in this respect, since they are committed to the view that if blame is an instance of rational criticism, both practices might lack their function in such a case. Second, it should be recalled that blame need not be an instance of rational criticism, a view which finds support in the literature. This view is also suggested by the fact that the two practices seem to differ with regard to what type of critical vocabulary they employ (e.g. 'crazy' versus 'bad'), the procedures recommended to acquire the appropriate results (e.g. pointing out suitable means versus pointing out other people's feelings), and the attitudes that accompany them (e.g. irritation versus resentment). We should not exclude the possibility that it might be justified for $\mathrm{S}^{*}$ to blame $\mathrm{S}$ for not having a desire to $\varphi$ even if it is rationally inaccessible to her and rational criticism would not fulfil its function. Moreover, we should not rule out the possibility that there are other ways for $\mathrm{S}$ to acquire a morally suitable desire than via a process of rational deliberation (see e.g. McDowell (1995: 6885)). Third, the distinction between rational criticism in the attributability sense and in the accountability sense means that my view is not committed to this consequence. In particular, S might be blamed (and
} 
might be responded that objectivists use 'rational' in a non-standard, technical, sense, which makes it possible to reconcile their view with my arguments. However, it can then be asked why we should pay any particular attention to a use of the term that fails to capture what arguably is an essential aspect of its ordinary sense.

\section{$7 \quad$ A Puzzle about Reasons and Rationality}

In Sect. 3, it was observed that the standard claim about the link between reasons and rationality in conjunction with subjectivism about rationality yields internalism, which is incompatible with the existence of categorical reasons, whereas the standard claim in conjunction with objectivism about rationality yields externalism, which is compatible with the existence of such reasons. It was then argued that subjectivism, but not objectivism, is able to account for the connection between rationality, mental functioning, and rational criticism, which is entailed by an ordinary, non-technical, sense of 'rational'.

Thus, we face a puzzle: While objectivism widely is considered to be a necessary condition for the existence of categorical reasons, this view fails to capture a central sense of 'rational'. The following notions are active in generating this puzzle: the standard claim, subjectivism, objectivism, and categorical reasons. Above I have argued for subjectivism and against objectivism. Further, we are presumably reluctant to draw the conclusion that there are not any categorical reasons. There seems to be only one way to solve the puzzle: to deny the standard claim. Now, this claim might be denied in different ways. It might be denied by maintaining that there is no relevant link between reasons and rationality. This alternative is incompatible with the notion that there is a close connection between reasons and rationality of which common parlance and the metaethical debate bear witness. However, the standard claim might also be denied by maintaining some other link between reasons and rationality. As far as I see, this is the only alternative that would enable us to accommodate both subjectivism, the existence of categorical reasons, and a suitable connection between reasons and rationality. In the next section, I sketch a version of this response to the puzzle.

rationally criticized) in the attributability sense although doing so would not have any prospect of influencing her actions or desires. 


\section{Brief Outline of a Solution}

In what follows, I will very briefly outline a view about reasons which denies the standard claim and replaces it with a distinction between requiring reasons and justifying reasons. The distinction is then combined with subjectivism about rationality. As we shall see, the resulting view means that the existence of categorical reasons, in the form of justifying reasons, is compatible with subjectivism. Needless to say, here I cannot provide a full defence of the view, but will merely indicate the possibility of it. ${ }^{41}$ Recall:

Standard Claim: If a person $\mathrm{S}$ has a normative reason to $\varphi$, then she would have a desire to $\varphi$ if she were practically rational.

As was observed in Sect. 3, this claim has an important implication: If S has a reason to $\varphi$, but lacks any desire to $\varphi$, she is irrational. It is plausible to assume that the standard claim is correct for certain reasons, e.g. certain prudential reasons. However, it also seems plausible to argue that it is not correct for all reasons, e.g. moral reasons. ${ }^{42}$ To illustrate, assume that Ada has a moral reason to, say, help a fellow human being who is in need. On the one hand, it seems plausible to assume that it would not be irrational for Ada to have a desire to perform the action in question. The fact that an action would help someone plausibly means that it is not irrational to have a desire to perform it. On the other hand, contra the standard claim, it seems implausible to insist that Ada needs to be irrational if she lacks such a desire. It seems possible to conceive of a person who is not irrational even if she lacks any desire to perform such actions. The most evident thing to say about people whose desires do not accord with their moral reasons is that they are morally insensitive or bad, not that they necessarily are irrational.

This suggests that there is a distinction between reasons for which the standard claim is correct (requiring reasons) and reasons for which it is not (justifying reasons): ${ }^{43}$

\footnotetext{
${ }^{41}$ I provide a fuller account of this view in Strandberg (manuscript).

${ }^{42}$ Gert (2004: esp. Ch. 2). Cf. Foot (1978 (1972): 157-173); Copp (2010: 141-165), and Copp (2015: 134-159). For a view related to the one defended here, see Chang (2004: 56-90).

${ }^{43}$ For this distinction, see e.g. Gert (2004: esp. Ch. 4) and Gert (2007: 319-322). My formulation of the distinction diverges substantially from Gert's.
} 
Requiring Reasons: A person $\mathrm{S}$ has a requiring reason to $\varphi$ insofar as $\varphi$ ing has a feature $\mathrm{F}$ such that (i) it would be irrational for $\mathrm{S}$ to lack a desire to $\varphi$, and (ii) it would not be irrational for $\mathrm{S}$ to lack a desire to $\varphi$ in the absence of $F^{44}$

Justifying Reasons: A person $\mathrm{S}$ has a justifying reason to $\varphi$ insofar as $\varphi$ ing has a feature $\mathrm{F}$ such that (i) it would not be irrational for $\mathrm{S}$ to have a desire to $\varphi$, and (ii) it would be irrational, or non-rational, for $S$ to have a desire to $\varphi$ in the absence of $\mathrm{F}^{45}$

Let us next recall subjectivism about rationality. Consider the first part of subjectivism (i): A person $\mathrm{S}$ is rational in the relevant respect insofar as she has the set of desires she would have were she to go through a process of rational deliberation which takes point of departure in her actual desires. Now, it is essential to notice that (i) is compatible with it not being irrational for $\mathrm{S}$ to have a desire to $\varphi$ which is not member of this set of desires given that ping has some other feature which explains why this is the case. It might also be the case that it would be irrational, or non-rational, for $\mathrm{S}$ to have this desire to $\varphi$ in the absence of such a feature. Moreover, the feature in question might be an external feature of ping, i.e. a feature that does not make any reference to S's actual or idealized desires, but concerns, for instance, the wellbeing of other people. Let us see why subjectivism is compatible with this possibility in more detail. First, according to (i) S needs to have desires that are part of the mentioned set of desires in order to be rational. That is, she is irrational if she lacks certain desires that are members of this set. However, this is compatible with it not being irrational for her to have a desire to $\varphi$ which is not member of this set given that ping has an external feature which explains why this is the case. Second, according to (i) S does not need to have any desire that is not member of this set of desires to be rational. That is, she is not irrational if she lacks any further desires. However, this is compatible with it not being irrational for $\mathrm{S}$ to have a desire to $\varphi$ given that $\varphi$ ing has the mentioned type of feature.

Consider next the second part of subjectivism (ii): It is not the case that $S$ in order to be rational needs to have any desire which is counterfactually independent of her set of actual desires. According to (ii), it is not irrational for $S$ to lack a desire to $\varphi$ which is counterfactually independent of her actual desires. However, on this claim it

\footnotetext{
${ }^{44}$ Given that ping does not have any other feature which has this function.

${ }^{45}$ Given that ping does not have any other feature which has this function.
} 
would not be irrational for $\mathrm{S}$ to have a desire to $\varphi$ which is counterfactually independent of her actual desires. That is, it would not be irrational for her to have this desire to $\varphi$ even if her set of actual desires had been entirely different from what it is. The explanation is that this is not a desire $\mathrm{S}$ is guaranteed to acquire as a result of having gone through a process of rational deliberation starting off in her actual desires.

To illustrate, return to Ada in cases 1 and 2. Ada has the desires she would have were she to go through a process of rational deliberation taking its point of departure in her actual desires. It follows on subjectivism that she does not need to have any further desires in order to be rational, in spite of her not having any desire to help other people in need or to avoid pain. However, it would not be irrational for Ada to have a desire to help another person in need, given that this type of action has some external feature which explains why this is the case. Moreover, it might be irrational, or non-rational, for her to have this desire in the absence of such an external feature. Similarly, it would not be irrational for Ada to have a desire to avoid pain, given that this type of action has some feature which explains this. Moreover, this desire- to help someone in need or avoid pain — might be counterfactually independent of her actual desires.

A person $\mathrm{S}$ has a justifying reason to $\varphi$ insofar as $\varphi$ ing has some feature $\mathrm{F}$ such that it would not be irrational for her to have a desire to $\varphi$ but it would be irrational, or non-rational, for her to have this desire in the absence of F. As we have seen, according to subjectivism the mentioned feature $\mathrm{F}$ might consist in an external feature of ping. Thus, Ada might have a categorical reason, in the form of justifying reason, to help someone in need, or avoid pain, in the sense that she would have this reason quite irrespective of what her actual desires consist in. ${ }^{46}$ In this paper, I do not have space to argue for a particular view about what such a feature consists in. However, elsewhere I argue that one type of external feature consists in ping being such that it supports the fulfilment of a desire another person would have were she to go through a process of rational deliberation which takes its starting point in her desires. Moreover, I argue that this external feature can be defended by employing the notion of coherence among desires in a manner representing a natural development of subjectivism about

\footnotetext{
${ }^{46}$ A person $S$ has a requiring reason to $\varphi$ insofar as $\varphi$ ing has a feature $F$ such that it would be irrational for her to lack a desire to $\varphi$ but not irrational for her to lack this desire in the absence of F. On subjectivism, it would be irrational for $\mathrm{S}$ to lack a desire only if it is member of the set of desires she would have were she go through a process of rational deliberation which starts off in her actual desires. It might be suggested that such a desire is a desire for a necessary means to fulfil some final desire which also is member of this set of rational desires.
} 
rationality. Accordingly, this feature might account for why Ada has a categorical moral reason, in the form of a justifying reason, to help another person in need.

It is evident that many issues need to be addressed in order for the outlined suggestion to provide a viable view of reasons. What is important to notice in the present context, however, is that it solves the puzzle outlined above. This view combines the distinction between requiring and justifying reasons with subjectivism about rationality. Subjectivism entails rational accessibility: In order to be rational, $\mathrm{S}$ needs to have a desire to $\varphi$ only if she would be able to acquire it via a process of rational deliberation. Since the suggested view entails rational accessibility, it accommodates the connection between rationality, mental functioning, and rational criticism in the way I explained earlier in the paper. Thus, it avoids the difficulties objectivism has to account for this connection. At the same time, it is compatible with the existence of categorical reasons in the form of justifying reasons.

In Sect. 6.1, we made two observations that provide further support to this view. First, arguments for objectivism standardly appeal to our notion of the connection between reasons and desires, rather than our notion of the connection between rationality and desires. In these arguments, it is typically maintained that $\mathrm{S}$ might have a moral reason to $\varphi$ quite irrespective of what her actual desires consist in, a notion which is accommodated by the present view. However, they do not typically insist that she would be irrational if she lacks a desire to $\varphi$, something which also confirms the view suggested here. The explanation why it might seem that such arguments provide support to objectivism is that they presume the standard claim, which, as we have seen, there are grounds to reject. Second, it was noticed that our notion of the connection between rationality and desires does not support objectivism. Most importantly, intuitively it does not seem to be the case that someone who has a moral reason to, say, help another person in need has to be irrational if she lacks a desire to do so, which also provides support to the present view. Moreover, it is problematic for objectivists to maintain that someone who has a prudential reason to, say, avoid pain would be irrational if she lacks a desire to do so, since the notion of what is bad with being in pain seems to entail having a desire not to be in this mental state. The present view leaves open the possibility that one might have a justifying reason to avoid pain even if it turns out that what is bad with being in this state does not have this connection to desire.

In Sect. 6.3, I indicated that the suggested view avoids an argument against internalism with regard to moral blame. It is generally assumed that it is justified to 
blame a person $\mathrm{S}$ for not ping only if she has a sufficiently strong reason to $\varphi$. Internalism claims that if $S$ has a reason to $\varphi$, she would have a desire to $\varphi$ if she were rational, where rationality is understood in line with subjectivism, which means that whether $\mathrm{S}$ has a reason to $\varphi$ would vary with her actual desires. However, it appears that $\mathrm{S}$ might be blamed for not ping quite irrespective of what her desires consists in. The view I suggest denies the standard claim while at the same time entailing subjectivism. This means that $S$ might have justifying reason to $\varphi$ in virtue of ping having a certain external feature. Thus, $S$ might have a justifying reason to $\varphi$ quite independently of what desires she has. Accordingly, this view leaves open the possibility that it is justified to blame $\mathrm{S}$ for not ping quite irrespective of what her actual desires happen to consist in.

\section{Conclusion}

In this paper, I have argued that subjectivism about rationality is able to account for an ordinary, non-technical, sense of 'rational' whereas objectivism about rationality is not. As we have seen, this leads to a puzzle: While objectivism is widely considered to be a necessary condition for the existence of categorical reasons, this view fails to capture this central sense of 'rational'. At the end of the paper, I briefly argued that this puzzle can be solved by abandoning the standard claim about the connection between reasons and rationality. As a result, there are categorical reasons also according to subjectivism about rationality.

Acknowledgment I am grateful for audiences in Gothenburg and Oslo for valuable comments on earlier versions of this paper. Special thanks are due to Andreas Brekke Carlsson for helpful discussions about reasons, rationality, and blameworthiness. I am also indebted to reviewers for insightful comments that have helped to improve the paper in numerous respects. The research presented in this paper was supported by the Swedish Research Council (grant number 2012-603).

\section{References}

Bagnoli, C. 2009. The Mafioso Case: Autonomy and Self-Respect. Ethical Theory and Moral Practice 12: 477-493.

Bedke, M. 2008. Practical Reasons, Practical Rationality, Practical Wisdom. Ethical Theory and Moral Practice 11: 85-111.

Brandt, R. 1979. A Theory of the Right and the Good. Oxford: Clarendon Press.

Bratman, M. 1987. Intention, Plans, and Practical Reasoning. Cambridge, Mass: Harvard University Press. 
Bratman, M. 2000. Reflection, Planning, and Temporally Extended Agency. Philosophical Review 109: 35-61.

Brink, D. 1992. A Puzzle about the Rational Authority of Morality. Philosophical Perspectives 6: 1-26. Broome, J. 2013. Rationality through Reasoning. Oxford: Blackwell.

Chang, R. 2004. Can Desires Provide Reasons for Action?' In Reason and Value, eds. R.J. Wallace, P. Pettit, S. Scheffler, and M. Smith, 56-90. Oxford: Clarendon Press.

Cohon, R. 1986. Are External Reasons Impossible? Ethics 96: 545-556.

Copp, D. 2010. Normativity, Deliberation, and Queerness. In A World Without Values, eds. R. Joyce and S. Kirchin, 141-166. Dordrecht: Springer.

Copp, D. 2015. Rationality and Moral Authority. In Oxford Studies in Metaethics, Vol. 10, ed. R. ShaferLandau, 134-159. Oxford: Oxford University Press.

Cullity, G. and B. Gaut. 1997. Introduction. Ethics and Practical Reason, eds. G. Cullity and B. Gaut, 127. Oxford: Clarendon Press.

Darwall, S. 1983. Impartial Reason. Ithaca: Cornell University Press.

Enoch, D. 2007. Rationality, Coherence, Convergence: A Critical Comment on Michael Smith's Ethics and the A Priori. Philosophical Books 48: 99-108.

Enoch, D. 2011. Taking Morality Seriously. A Defense of Robust Realism. Oxford: Oxford University Press.

Finlay. S. 2009. The Obscurity of Internal Reasons. Philosophers' Imprint 9: 1-22.

Finlay, S. and M. Schroeder. 2008. Reasons for Action: Internal vs. External. Stanford Encyclopedia of Philosophy. http://plato.stanford.edu/entries/reasons-internal-external.

Fischer, J. and N. Tognazzini. 2011. The Physiognomy of Responsibility. Philosophy and Phenomenological Research 72: 381-417.

FitzPatrick, W. 2004. Reasons, Value, and Particular Agents. Mind 113: 285-318.

FitzPatrick, W. 2005. The Practical Turn in Ethical Theory: Korsgaard's Constructivism, Realism, and Nature of Normativity. Ethics 115: 651-691.

Foot, P. 1978 (1972)). Morality as a System of Hypothetical Imperatives. In Virtues and Vices, 157-173. Oxford: Blackwell.

Gert, J. 2004. Brute Rationality. Cambridge: Cambridge University Press.

Gert, J. 2007. Normative Strength and the Balance of Reasons. Philosophical Review 52: 533-562.

Goldman, A. 2009. Reasons from Within. Oxford: Oxford University Press.

Heathwood, C. 2011. Desire-Based Theories of Reasons, Pleasure, and Welfare. In Oxford Studies in Metaethics, Vol. 6, ed. R. Shafer-Landau, 79-106. Oxford: Oxford University Press.

Hooker, B. 1987. Williams’ Argument Against External Reasons. Analysis 47: 42-44.

Hooker, B. and B. Streumer. 2004. Procedural and Substantive Rationality. In The Oxford Handbook of Rationality, eds. A.R. Mele and P. Rawling, 110-131. Oxford: Oxford University Press.

Hubin, D. 1999. Converging on Values. Analysis 59: 355-361.

Joyce, R. 2001. The Myth of Morality. Cambridge: Cambridge University Press.

Kerstein, S. 2006. Reason, Sentiment, and Categorical Imperatives. In Contemporary Debates in Moral Theory, ed. J. Dreier, 129-143. Oxford: Blackwell.

Korsgaard, C. 1986. Skepticism about Practical Reason. Journal of Philosophy 83: 5-25.

Korsgaard, C. 1996. The Sources of Normativity. Cambridge: Cambridge University Press.

Lillehammer, H. 2002. Moral Realism, Normative Reasons, and Rational Intelligibility. Erkenntnis 57: 47-69.

Lubin, D. 2009. External Reasons. Metaphilosophy. 40: 273-290.

McDowell, J. 1995. Might there be External Reasons?' In World, Mind, and Ethics, eds. J.E.J. Altham and R. Harrison, 68-85. Cambridge: Cambridge University Press.

Markovits, J. 2014. Moral Reason. Oxford: Oxford University Press.

Millgram, E. 1996. Williams's Argument Against External Reasons. Nô̂s 30: 197-220.

Nagel, T. 1970. The Possibility of Altruism. Princeton: Princeton University Press.

Parfit, D. 2011. On What Matters. Oxford: Oxford University Press.

Quinn, W. 1993. Putting Rationality in its Place. In Morality and Action, 228-255. Cambridge:

Cambridge University Press.

Railton, P. 1986. Facts and Values. Philosophical Topics 14: 5-31.

Ridge, M. 2014. Impassioned Belief. Oxford: Oxford University Press.

Scanlon, T.M. 1998. What We Owe to Each Other. Cambridge, Mass.: Harvard University Press.

Scanlon, T.M. 2008. Moral Dimensions: Permissibility, Meaning, Blame. Cambridge, MA: Harvard University Press.

Setiya, K. 2004. Against Internalism. Noûs 38: 266-298.

Setiya, K. 2007. Reasons without Rationality. Princeton: Princeton University Press. 
Shafer-Landau, R. 2003. Moral Realism. A Defence. Oxford: Clarendon.

Shemmer, Y. 2007. Desires as Reasons. Philosophy and Phenomenological Research 75: 326-348.

Skorupski, J. 2007. Internal Reasons and the Scope of Blame. In Bernard Williams, ed. A. Thomas, 73

103. Cambridge: Cambridge University Press.

Skorupski, J. 2010. The Domain of Reasons. Oxford: Oxford University Press.

Smith, M. 1994. The Moral Problem. Oxford: Blackwell.

Smith, M. 1995. Internal Reasons. Philosophy and Phenomenological Research 55: 109-131.

Smith, M. 2011. Deontological Moral Obligations and Non-Welfarist Agent-Relative Values. Ratio 4: $351-363$

Smith, M. 2012. Agents and Patients. Proceedings of the Aristotelian Society 112: 309-331.

Sobel, D. 1999. Do the Desires of Rational Agents Converge? Analysis 59: 137-147.

Sobel, D. 2001. Explanation, Internalism, Reasons for Action. Social Philosophy and Policy 19: $218-235$.

Sobel, D. 2011. Parfit's Case against Subjectivism. In Oxford Studies in Metaethics, Vol. 6, ed. R.

Shafer-Landau, 53-78. Oxford: Oxford University Press.

Strandberg, C. (Manuscript). Between Internalism and Externalism about Reasons.

Svavarsdóttir, S. 2008. The Virtue of Practical Rationality. Philosophy and Phenomenological Research 77: 1-33.

Wallace, J. 1994. Responsibility and the Moral Sentiments. Cambridge, MA: Harvard University Press.

Wallace, J. 1999. Three Conceptions of Rational Agency. Ethical Theory and Moral Practice 2: $217-242$.

Watson, G. 1996. Two Faces of Responsibility. Philosophical Topics 24: 227-248.

Williams, B. 1981. Internal and External Reasons. In Moral Luck, 101-113. Cambridge: Cambridge University Press.

Williams, B. 1995 (1989). Internal Reasons and the Obscurity of Blame. In Making Sense of Humanity, 35-45. Cambridge: Cambridge University Press. 